\title{
Pulvertagung zeigt aktuelle Trends und neue Anwendungen
}

\author{
Automatisierungslösungen, neue Anwendungsbereiche für Pulverbeschichtungen und \\ Branchentrends standen auf dem diesjährigen EPS-Pulvertreff im Blickpunkt. In 17 Vorträgen und \\ einer begleitenden Ausstellung informierten sich die Teilnehmer am 16. und 17. Oktober in München \\ über neueste Erkenntnisse rund um die Pulverbeschichtung.
}

Seit 37 Jahren ist der EPS-Pulvertreff eine feste Institution und Treffpunkt der Pulverbranche. Auch in diesem Jahr bot die Tagung einen traditionell hochwertigen Rahmen, um sich über aktuelle Entwicklungen und neue Anwendungen auf dem Gebiet der Pulverbeschichtung zu informieren und sein Netzwerk mit Branchenkollegen zu pflegen.

An zwei Veranstaltungstagen konnten die Teilnehmer aus Lohn- und inhouse-
Beschichtung sowie Anlagen- und Pulverlackherstellung unterschiedlichen Vorträgen aus Wissenschaft, Industrie und Praxis folgen und sich auf einer begleitenden Ausstellung weitergehend informieren.

\section{Pulverbeschichtung im Querschnitt}

Die insgesamt 17 Vorträge lieferten einen Querschnitt durch verschiedene Aspekte der Pulverbeschichtung. Themen waren

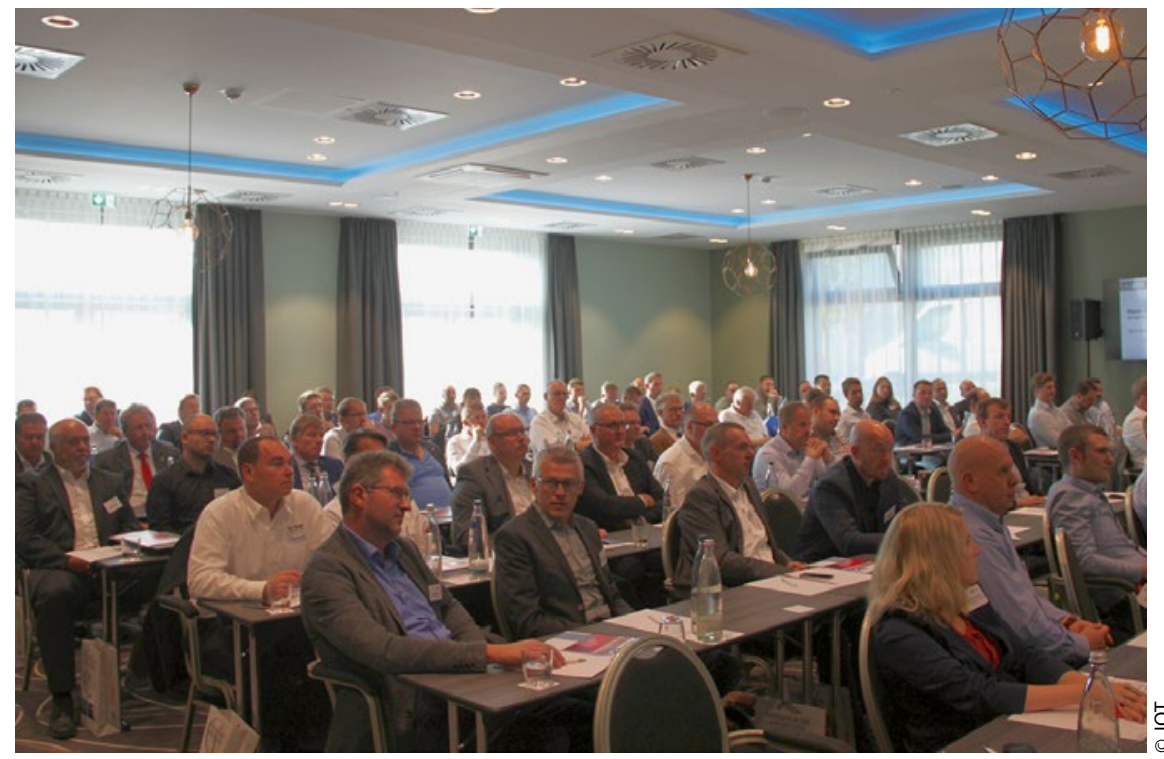

Bild 1 > Seit 37 Jahren eine feste Institution - in diesem Jahr informierte der EPS-Pulvertreff in 17 Vorträgen unter anderem über innovative Automatisierungslösungen und neue Anwendungsbereiche für Pulverbeschichtungen unter anderem Automatisierungslösungen, die Roboterbeschichtung sowie Beschichtungen in Losgröße 1. Darüber hinaus reichte das Spektrum der Vorträge von Verfahren zum Messen von Schichtdicken und die Anwendung schneller Pulverlacke über Vorbehandlungsprozesse bis hin zur Fördertechnik für Schwerlastteile. Anschauliche Anwendungsbeispiele und die Vorstellung neuer Anlagenkonzepte durch Anwender rundeten das Programm ab. Ein gemeinsames Get-together mit Abendessen in rustikal bayrischer GasthofAtmosphäre schloss den ersten Veranstaltungstag. In zwanglosem Ambiente ergaben sich hier Möglichkeiten für interessante Gespräche mit Kollegen und die Pflege der Branchenkontakte.

Um der engen Terminsituation für Teilnehmer und Aussteller Rechnung zu tragen, fand die EPS-Tagung in diesem Jahr erstmals im Oktober und nicht wie zuvor im März statt. Zudem bot das neue Leonardo Hotel im Münchner Stadtteil Neuperlach erstmalig den geschmackvollen und modernen Rahmen für die Veranstaltung.

Die neue Terminierung im Herbst wird auch im nächsten Jahr beibehalten. Der EPS-Pulvertreff 2019 wird am 5. und 6. November 2019 in München stattfinden.

Weitere Informationen finden Sie unter: www.jotlive.de 